\title{
Semen characteristics in free-living koalas (Phascolarctos cinereus)
}

\author{
D. E. Wildt ${ }^{1 *}$, M. Bush ${ }^{1}$, S. J. O'Brien ${ }^{2}$, N. D. Murray ${ }^{3}$, A. Taylor ${ }^{3}$ and \\ J. A. Marshall Graves ${ }^{3}$ \\ ${ }^{I}$ National Zoological Park, Smithsonian Institution, Washington, DC 20008, USA; ${ }^{2}$ Section of \\ Genetics, National Cancer Institute, Frederick, MD 21702, USA; and ${ }^{3}$ Department of Genetics and \\ Human Variation, La Trobe University, Bundoora, Victoria, Australia
}

\begin{abstract}
Summary. Spermic electroejaculates (range in motile sperm/ejaculate, $0.50-122.9 \times 10^{6}$; mean \pm s.e.m., $38.6 \pm 4.9$ ) were recovered from 47 of 48 adult koalas captured from 3 wild populations in Australia. Semen was characterized by (i) a high density of globular bodies, which prevented the estimation of sperm motility without dilution; (ii) a brownish colour; and (iii) an acidic $\mathrm{pH}$. Spermatozoa were categorized on the basis of 10 head forms, most cells being a curved or hooked shape. The koala populations differed in sperm concentration and motility ratings, but not in testes size, testosterone production or proportions of spermatozoa with various head shapes. These data confirm that free-living koalas normally produce spermatozoa with a high incidence of structural heterogeneity almost solely confined to the head region; and demonstrate the utility and safety of conventional gamete and endocrine studies, approaches which will be useful for determining the impact of genetic isolation and venereal disease on species fertility.
\end{abstract}

Keywords: koala; marsupial; semen; electroejaculation; spermatozoa; testis; testosterone

\section{Introduction}

The reproductive physiology of the koala (Phascolarctos cinereus) has not been studied extensively, in part because of the protected conservation status of the species. Female koalas appear to be seasonally polyoestrous, and gestation is about 35 days; however, the onset of breeding, regardless of season, appears dependent on the presence of pouch young and lactation (Smith, 1979; Handasyde, 1986). Oestrous cycle duration has been estimated to be either shorter ( $\sim 27-30$ days; Smith, 1979; Brown, 1988) or the same length (35 days; Handasyde, 1986) as gestation. This variability may be related to the possibility that a male must be present for ovulation to occur (Handasyde et al., 1988). Koala spermatozoa appear to be structurally heterogeneic (Harding, 1979; Harding et al., 1987; Temple-Smith \& Taggart, 1988), but all material evaluated to-date has been from necropsied animals. To our knowledge, there are no reports on semen characteristics from living animals.

The koala is a specialized arboreal folivore which forages almost exclusively on leaves from certain eucalyptus species. Native habitats have become fragmented and shrunken so that the species now exists in many isolated populations exclusively in eastern Australia (Gordon, 1988; Lee \& Martin, 1988; Reed et al., 1988). The impact of isolation on the molecular genetic profile and reproductive performance is unknown and complicated by the predisposition of koalas to infections of the reproductive tract, a characteristic noted more than 70 years ago (O'Donoghue, 1916). The predominant pathogen is a host-specific strain of Chlamydia psittaci (Brown et al., 1984;

\footnotetext{
*Author for correspondence: Telephone (202) 673-4793 FAX (202) 673-4733.
} 
McColl et al., 1984), a bacterium causing a condition remarkably similar to pelvic inflammatory disease in humans (Lee \& Martin, 1988). Although the precise effects of $C$. psittaci infections in the koala are unkown, this disease appears to be the major cause of species infertility, morbidity and mortality (Carlisle et al., 1989).

Obtaining baseline data on reproductive characteristics is a first step to understanding the effects of genetics and disease on fertility, establishing captive breeding colonies or choosing appropriate conservation strategies for wild populations. Our objectives were to determine the effectiveness of electroejaculation for collecting koala sperm under field conditions; and to document conventional semen traits and testes morphometry for free-living males. This information is being used in parallel studies to evaluate genetic variability among koala populations using molecular techniques (S. J. O’Brien, A. Taylor, N. D. Murray \& J. A. M. Graves, unpublished).

\title{
Materials and Methods
}

\begin{abstract}
Animals and habitats. Forty-eight adult, male koalas were evaluated in February from 3 Victorian populations within $140 \mathrm{~km}$ of Melbourne $\left(\sim 145^{\circ}\right.$ longitude; $38^{\circ}$ latitude): Brisbane Ranges National Park $(n=20)$; French Island $(n=20)$ and Phillip Island $(n=8)$ in Australia. According to Lee \& Martin (1988), this is a time of the year when koalas are sexually active. The Brisbane Ranges National Park ( $\sim 7500$ ha) contains a population of several thousand koalas. French Island and Phillip Island are adjacent to the southern continental coast and support several thousand and $\sim 200$ koalas, respectively. The relatedness within and among the 3 populations is unclear, which is the primary reason for concurrent genetic studies. Records indicate that a small population of koalas was released onto French Island, probably in the late 1800s (Warneke, 1978). Koalas were introduced onto Phillip Island several times, the earliest release occurring in about 1870 (Warneke, 1978). For management purposes, koalas were removed from French Island on numerous occasions after 1923 and released into native populations, including the Brisbane Ranges National Park (R. M. Warneke, personal communication). The reproductive performance of the various populations is unknown, but there is a high incidence of infection with C. psittaci in koalas on Phillip Island (Lee \& Martin, 1988). The disease is much less severe in the Brisbane Ranges population and is absent on French Island.
\end{abstract}

Animal capture and anaesthesia. Animals were identified in trees during daylight and captured according to the method of McNally (1957). An aluminum extension pole was used to place a rope noose around the koala's neck. Once the noose was secure, a flag was attached to the pole, extended above the koala and waved. Each male backed down to the base of the tree where it could be physically restrained, placed in a cloth bag and later crated. Usually animals were moved at least $1 \mathrm{~km}$ to a base camp for anaesthesia, blood sampling and semen collection. All animals were weighed (average body weight, $11 \cdot 1 \pm 0.1 \mathrm{~kg}$, range, $9 \cdot 1-14.0 \mathrm{~kg}$; population means $11 \cdot 2 \pm 0.2 \mathrm{~kg}$ in Brisbane Ranges, $11 \cdot 2 \pm 0.2 \mathrm{~kg}$ in French Island and $10.9 \pm 0.4 \mathrm{~kg}$ in Phillip Island, $P>0.05$ ). A blood sample (before anaesthesia; $7 \mathrm{ml}$ ) was collected by puncturing the cephalic vein. Subsequent blood sampling and electroejaculation were performed after each animal was induced and maintained in a surgical plane of anaesthesia using a combination of tiletamine and zolazepam hydrochloride (Telazol, A. H. Robbins, Inc., Richmond, VA, USA). Details on the dose and effectiveness of Telazol in free-ranging koalas have been described recently (Bush et al., in press). Ear tuft hair was clipped so that animals could be identified later to avoid redundant captures. All koalas appeared fully recovered within $6 \mathrm{~h}$ of initial Telazol injection and each was returned to the original capture site.

Testes measurement and semen collection and evaluation. After each male was in a surgical plane of anaesthesia, the length and width of each testis was measured using laboratory calipers and the values were converted to testicular volume using the formula $\mathrm{V}=4 / 3 \pi a b^{2}$, where $a$ is half the length and $b$ is the width (Howard et al., 1986). The volumes of each testis were combined to obtain total testicular volume/male. Semen collection and evaluation were performed using minor adaptations of a previous electroejaculation regimen (Wildt et al., 1983, 1987, 1989; Howard et al., 1986). The nonerect penis of the koala normally is withdrawn into the body in a type of preputial sac formed by an invagination of skin adjacent to the rectal opening (Tyndale-Biscoe \& Renfree, 1987). The penis was everted from the anus, cleaned with sterile saline and dried. A lubricated probe $1 \mathrm{~cm}$ in diameter (P.T. Electronics, Boring, OR, USA) with 3 longitudinal electrodes (each $3.2 \mathrm{~cm}$ long) was inserted $\sim 6 \mathrm{~cm}$ into the rectum with the electrodes orientated ventrally. The electroejaculator was an a.c. $60-\mathrm{Hz}$ sine-wave unit (P.T. Electronics), and the regimented electroejaculation sequence consisted of 3 series of 30 stimuli each with a $3-5$ min rest period between series (total electroejaculation interval $20 \cdot 3 \pm 1 \cdot 2 \mathrm{~min}$ ). Series 1,2 and 3 were initiated at 1,2 and $3 \mathrm{~V}$, respectively, with a $1 \mathrm{~V}$ increment after every 10 stimuli. At the end of Series 3, all semen aliquants were combined and total ejaculate volume was measured. Ejaculate colour was noted, semen $\mathrm{pH}$ was assessed using colormetric $\mathrm{pH}$ paper (Colorphast Indicator Sticks, E. Merck, Darmstadt, FRG) and sperm concentration was determined using a standard haemocytometer method (Wildt et al., 1983). Estimates of sperm motility were impossible using raw ejaculate and required a 1:6 dilution in Biggers, Whitten and Whittingham medium (BWW; Biggers et al., 1971) maintained at $\sim 37^{\circ} \mathrm{C}$. After gently mixing, a $2 \mu \mathrm{l}$ sample of the diluted ejaculate was placed at $37^{\circ} \mathrm{C}$ on a glass slide under a cover slip and evaluated for sperm \% motility and status (forward progression) using previous methods and criteria (Wildt et al., 
1983, 1989; Howard et al., 1986). Sperm status was a subjective evaluation of the type of forward movement of the sperm cell based on a scale of 0 (no movement) to 5 (steady, rapid forward progression). The number of motile sperm/ ejaculate was calculated by multiplying the ejaculate volume by the sperm concentration by the sperm $\%$ motility rating.

For gross morphological assessments, $50 \mu \mathrm{l}$ of the BWW-diluted ejaculate was fixed in $1 \%$ glutaraldehyde, and $200 \mathrm{sperm} /$ collection were examined using phase-contrast microscopy $(1000 \times)$ (Pursel \& Johnson, 1974). Among spermatozoa, the middle piece and principal piece appeared uniform, but head structure was highly variable. Individual cells were categorized as having one of 10 head shapes (Fig. 1).

Serial blood sampling and testosterone analyses. A blood sample was collected from all koalas while fully conscious and immediately before anaesthesia induction. Government permit restrictions did not allow serial blood sampling of the French Island and Phillip Island populations, but 17 of the males from the Brisbane Ranges National Park were sampled immediately before injecting the anaesthetic $(7 \mathrm{ml} \mathrm{sample})$, again after anaesthesia and immediately before electroejaculation $(8.2 \pm 0.7 \mathrm{~min}$ after the pre-anaesthesia sample), immediately after the end of electroejaculation (Series 3 ) and at 15 -min intervals for $1 \mathrm{~h}$ (total samples, $n=7$ ). The 6 samples taken after anaesthesia each contained $4 \mathrm{ml}$, so a total of $31 \mathrm{ml}$ of blood was collected/male. Sera were recovered after centrifugation and placed on dry ice until returned to the laboratory and stored at $-20^{\circ} \mathrm{C}$. Serum testosterone was analysed using a commercialy available testosterone ${ }^{125}$ I kit (Nosolvex; Radioassay System Labs., Inc., Carson, CA, USA) which employed rabbit antitestosterone-19-carboxymethyl-ether bovine serum albumin as the antiserum. This antibody has the following crossreactivities: $100 \%$ with testosterone; $10.3 \%$ with $5 \alpha$-dihydrotestosterone; and $<1 \%$ with $5 \beta$-dihydrotestosterone, androstenedione, androstanedione, androsterone, epiandrosterone, oestrone, oestradiol-17 $\beta$, oestriol, progesterone and corticosterone. This assay has been used in our laboratory for a range of species (Wildt et al., 1987, 1988, 1989; Brown et al., 1988) and was validated for koala serum by demonstrating recovery of mass. Upon addition of $0,0-1$, $0 \cdot 25,0 \cdot 5,1 \cdot 0,2 \cdot 5$ and $5 \cdot 0 \mathrm{ng}$ testosterone to $25 \mu \mathrm{l}$ koala serum, $0.24,0.33,0.49,0.75,1 \cdot 27,2.82$ and $5.43 \mathrm{ng}$ was recovered, respectively, after subtracting endogenous hormone $(r=0.99)$. Inhibition curves for the testosterone standard and the serum pools were parallel. Assay sensitivity was $0.01 \mathrm{ng} /$ tube and the inter- and intra-assay coefficients of variation were $10 \cdot 8$ and $10 \cdot 1 \%$, respectively.

Statistical analyses. Values are reported as the mean \pm s.e.m. Differences in semen characteristics, testes volume and testosterone concentrations among populations were analysed using a Student's $t$ test. Correlations were calculated on a preprogrammed desk-top calculator.

\section{Results}

Electroejaculation elicited immediate penile erection in all males, which was sustained within each semen collection series. Spermic ejaculates were recovered from 47 of 48 males $(97.9 \%)$. One male had a palpable swollen and hardened epididymis unilaterally and produced $1.4 \mathrm{ml}$ of aspermic fluid. Thirty-three $(68 \cdot 8 \%), 37(77 \cdot 1 \%)$ and $35(72 \cdot 9 \%)$ koalas ejaculated spermatozoa in electroejaculation Series 1, 2 and 3, respectively. Eight males $(16.7 \%)$ did not produce a spermic ejaculate until Series 3; on $12(25 \%)$ occasions, sperm were produced in Series 1 and 2, but not Series 3. Fifteen males (31.2\%) urinated during electroejaculation, but, in all cases, urination was transitory and did not impair subsequent collection of motile spermatozoa. Urine contamination immediately reduced sperm motility to zero.

Semen was viscous, and the initial ejaculum was creamy-white and contained no sperm. The spermic fraction was characterized by a brownish fluid of a muddy appearance. Four males produced a plug-like coagulum during Series 2 or 3, which did not dissolve at ambient temperature. Microscopic examination of raw semen revealed only densely packed, rounded, globular cells; individual spermatozoa could not be clearly identified. Estimates of sperm motility were possible only after dilution (1 part semen:6 parts BWW). Average and range values for various semen characteristics are presented in Table 1 . The $\mathrm{pH}$ of 40 of the 47 ejaculates $(85.1 \%)$ was 6.5 or less; a neutral $\mathrm{pH}$ was measured in a single semen sample. Although there was considerable variation in sperm concentration $/ \mathrm{ml}$ of ejaculate among animals, sperm motility ratings were relatively consistent; e.g. the rating for 36 of the 47 ejaculates $(76.6 \%)$ was $70-90 \%$.

The head regions of all but $\sim 1 \%$ of spermatozoa were hooked or curved in shape (Fig. 1, Table 1; exception was type $\mathrm{X}$ ). The degree of bending varied from a modest angling of the head midregion (type VI) and tip (type VIII) to severe bending so that the head tip extended to (type III) or beyond (type VII) the head-neck attachment region. Most sperm showed bending of the head 
Table 1. Average \pm s.e.m. (and ranges) semen characteristics for 47 free-ranging koalas subjected to a standardized electroejaculation regimen

\begin{tabular}{cc}
\hline Ejaculate volume $(\mathrm{ml})$ & $1 \cdot 3 \pm 0 \cdot 1(0 \cdot 1-3 \cdot 8)$ \\
pH & $6 \cdot 1 \pm 0 \cdot 1(5 \cdot 2-7 \cdot 0)$ \\
Sperm Concentration/ml $\left(\times 10^{-6}\right)$ & $56 \cdot 4 \pm 12 \cdot 2(2-485)$ \\
Motility $(\%)$ & $74 \pm 2(40-90)$ \\
Forward progression status $(0-5)^{*}$ & $3 \cdot 7 \pm 0 \cdot 1(1 \cdot 5-4 \cdot 5)$ \\
Motile sperm/ejaculate $\left(\times 10^{-6}\right)$ & $38 \cdot 6 \pm 4 \cdot 9(0 \cdot 5-122 \cdot 9)$ \\
Head structure (type) & \\
I & $23 \cdot 2 \pm 1 \cdot 9$ \\
II & $19 \cdot 2 \pm 1 \cdot 7$ \\
III & $14 \cdot 9 \pm 1 \cdot 4$ \\
IV & $10 \cdot 3 \pm 1 \cdot 1$ \\
V & $9 \cdot 2 \pm 0 \cdot 9$ \\
VI & $9 \cdot 0 \pm 1 \cdot 0$ \\
VII & $7 \cdot 1 \pm 1 \cdot 0$ \\
VIII & $3 \cdot 4 \pm 0 \cdot 4$ \\
IX & $2 \cdot 1 \pm 0 \cdot 3$ \\
X & $1 \cdot 6 \pm 0 \cdot 3$ \\
\hline
\end{tabular}

$*_{0}=$ no movement, 5 = steady, rapid forward progression.

†See Fig. 1.

midregion, resulting in a $90^{\circ}$ (type II), $180^{\circ}$ (type I) or almost $360^{\circ}$ (type III) curvature. The heads of $\sim 9 \%$ of spermatozoa were sigmoid-shaped (type V).

For all koalas, testes volume averaged $6 \cdot 8 \pm 0 \cdot 2 \mathrm{~cm}^{3}$ (range $3 \cdot 3-9 \cdot 4 \mathrm{~cm}^{3}$ ). This wide range did not reflect the relative uniformity amongst most males. Only 1 and 4 koalas produced combined testes volumes of $<4.5 \mathrm{~cm}^{3}$ and $>9.0 \mathrm{~cm}^{3}$, respectively; and, overall, there was no relationship between testes volume and any electroejaculate characteristic, including motile sperm/ejaculate $(r=-0.06, P>0.05)$.

Overall, serum testosterone concentration in the first blood sample collected (before anaesthesia) averaged $0 \cdot 62 \pm 0 \cdot 14 \mathrm{ng} / \mathrm{ml}(0 \cdot 1-4 \cdot 7)$. Seven males $(14 \cdot 6 \%)$ produced testosterone concentrations of $>1.0 \mathrm{ng} / \mathrm{ml}$. There was only modest variability in circulating testosterone concentrations over time in serial sampled koalas (representative temporal profiles depicted in Fig. 2). Testosterone concentrations increased or decreased by $\geqslant 0.3 \mathrm{ng} / \mathrm{ml}$ during the bleeding interval in $2(11.8 \%)$ and $5(29.4 \%)$ males, respectively. Using this criterion, testosterone did not change over time in $9(52.9 \%)$ koalas and, in one male $(\# 18)$, testosterone decreased and then increased during the 98 -min sampling period (Fig. 2).

There were no differences $(P>0 \cdot 05)$ between populations in testes volume, ejaculate volume or testosterone concentrations (Table 2) or in the proportion of sperm with different head shapes (data not shown). In contrast, Brisbane Ranges koalas produced more $(P<0.05) \mathrm{sperm} / \mathrm{ml}$ of ejaculate, motile sperm/ejaculate and higher $(P<0.05)$ motility ratings than males from French Island. Fewer $(P<0.05)$ motile sperm/ejaculate were recovered from the Phillip Island koalas than from those from the Brisbane Ranges.

\section{Discussion}

Electroejaculation has been used with equivocal success in marsupials (Rodger, 1978; Rodger \& White, 1975, 1978). No fluid is released during electroejaculation of the Tasmanian devil (Sarcophilus harrisii) and eastern native cat (Dasyurus viverrinus) whereas the same technique results in copious prostatic secretions and no sperm in the red kangaroo (Macropus rufus) and eastern grey kangaroo (Macropus giganteus) (Rodger, 1978). In contrast, high-quality spermic ejaculates have been recovered consistently from electroejaculated brush tail possums (Trichosurus 


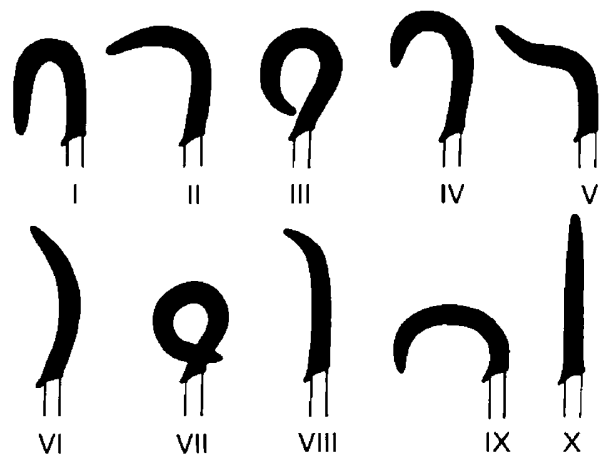

Fig. 1. Sperm head shapes identified in electroejaculates of free-living koalas.

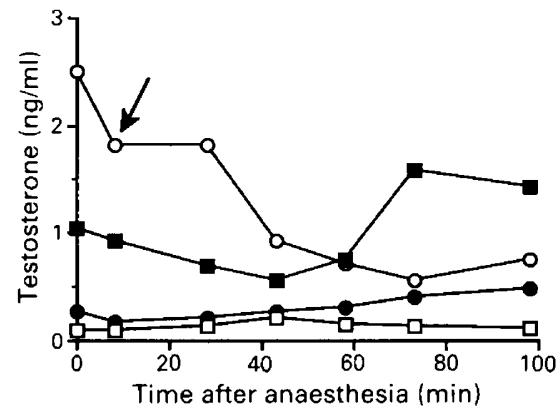

Fig. 2. Serum testosterone profiles in representative, free-living male koalas (numbers $4(\bullet), 14$ $(\bigcirc), 15(\square)$ and $18(\square)$ ) captured, anaesthetized and subjected to electroejaculation. The time 0 value is from the blood sample collected while the male was fully conscious and immediately before anaesthesia was induced with tiletamine and zolazepam hydrochloride. The second time point (arrow) is the blood sample taken after a surgical plane of anaesthesia was induced and immediately before electroejaculation onset. The third and subsequent blood samples were collected after electroejaculation.

Table 2. Average $( \pm$ s.e.m) combined testes volume, semen characteristics and serum testosterone concentrations in free-ranging koalas from 3 populations in Australia

\begin{tabular}{lccccccc}
\hline & $\begin{array}{c}\text { Testes } \\
\text { volume } \\
\left(\mathrm{cm}^{3}\right)\end{array}$ & $\begin{array}{c}\text { Ejaculate } \\
\text { volume } \\
(\mathrm{ml})\end{array}$ & $\begin{array}{c}\text { Sperm count/ml } \\
\text { ejaculate } \\
\left(\times 10^{-6}\right)\end{array}$ & $\begin{array}{c}\text { Sperm } \\
\text { motility } \\
(\%)\end{array}$ & $\begin{array}{c}\text { Sperm } \\
\text { status }\end{array}$ & $\begin{array}{c}\text { Motile sperm/ } \\
\text { ejaculate } \\
\left(\times 10^{-6}\right)\end{array}$ & $\begin{array}{c}\text { Serum } \\
\text { testosterone } \\
(\mathrm{ng} / \mathrm{ml})\end{array}$ \\
\hline $\begin{array}{c}\text { Brisbane ranges } \\
(n=20)\end{array}$ & $6 \cdot 3 \pm 0 \cdot 3$ & $1 \cdot 2 \pm 0 \cdot 2$ & $69 \cdot 7 \pm 15 \cdot 2^{\mathrm{a}}$ & $79 \pm 2^{\mathrm{a}}$ & $4 \cdot 0 \pm 0 \cdot 1^{\mathrm{a}}$ & $52 \cdot 1 \pm 8 \cdot 5^{\mathrm{a}}$ & $0 \cdot 46 \pm 0 \cdot 14$ \\
$\begin{array}{c}\text { French Island } \\
(n=20)\end{array}$ & $7 \cdot 0 \pm 0 \cdot 3$ & $1 \cdot 6 \pm 0 \cdot 2$ & $29 \cdot 5 \pm 5 \cdot 8^{\mathrm{b}}$ & $70 \pm 4^{\mathrm{b}}$ & $3 \cdot 4 \pm 0 \cdot 2^{\mathrm{b}}$ & $31 \cdot 3 \pm 6 \cdot 3^{\mathrm{b}}$ & $0.90 \pm 0.32$ \\
$\begin{array}{c}\text { Phillip Island } \\
(n=20)\end{array}$ & $7 \cdot 0 \pm 0 \cdot 5$ & $0.9 \pm 0.3$ & $80 \cdot 5 \pm 58 \cdot 5^{\mathrm{ab}}$ & $74 \pm 6^{\mathrm{ab}}$ & $3 \cdot 6 \pm 0 \cdot 9^{\mathrm{ab}}$ & $19 \cdot 9 \pm 5 \cdot 0^{\mathrm{b}}$ & $0 \cdot 53 \pm 0 \cdot 37$ \\
\hline
\end{tabular}

Values within columns with different superscripts differ $(P<0 \cdot 05)$. 
vulpecula) (Rodger, 1978). Radiographic observations of the brush tail possum, tammar wallaby (Macropus eugenii) and Northern brown bandicoot (Isoodon macrourus) reveal that marsupials differ with respect to positioning of the probe electrodes and the number of electrode pairs required to elicit ejaculatory contractions (Rodger \& Pollitt, 1981). In the present study, spermic ejaculates were recovered from all but a single koala (a male apparently experiencing epididymitis), and the numbers of sperm recovered/ejaculate were in the range reported for 4 possum, 6 wallaby and 40 possum electroejaculates (Rodger, 1978; Rodger \& Pollitt, 1981). The relative ease of recovering koala sperm by electroejaculation suggests that the mechanisms for eliciting ejaculation in this species may be less complex than for other marsupials.

Electroejaculation in possums causes the prostatic and membranous urethra to fill with the fluid infused via the ductus deferens, and the bladder neck to close (Rodger \& Pollitt, 1981). Eliminating the stimulus allows the upper urethral content to empty externally as a bolus. A similar mechanism may exist in koalas, as packed globular cells, presumably prostatic bodies, were the predominant constituent of seminal fluid. The koala is known to have a prominent prostate (Rodger \& Hughes, 1973). There are numerous descriptions of the prostate morphology of marsupials, but little information is available on the function of this accessory gland, although prostate size appears to be related to seasonal variation in testosterone production (Todhunter \& Gemmell, 1987). In the possum (Rodger \& Suter, 1978) and tammar wallaby (Rodger \& White, 1975), the prostate is the source of large globular spheres or prostatic bodies which are produced by a pinching off of the distal cytoplasm of epithelial cells (Rodger \& Hughes, 1973). The impact of prostatic secretions on koala ejaculate is unknown and perhaps is the cause of the unusually acidic seminal pH. In other marsupials, prostatic bodies frequently are associated with clumped and immotile sperm, suggesting that these globules may be deleterious to sperm viability (Rodger \& White, 1978). Prostatic bodies clearly present problems in purifying and isolating sperm for further studies (Rodger \& Pollitt, 1981). For the koala, simply adding a common tissue culture medium (BWW) to raw semen diluted the ejaculate sufficiently to evaluate sperm motility accurately.

Interestingly, a creamy white koala ejaculate (a colour generally associated with sperm-rich semen in most mammals) was unrelated to the presence of sperm. In all cases, the subsequent release of a brownish fluid indicated the temporal ejaculatory release of sperm. Unlike that in certain marsupials, especially species in the Macropodinae (Poole \& Pilton, 1964; Rodger \& White, 1975), koala semen did not coagulate. A gel-like coagulum was released, however, by 4 males later in the electroejaculation procedure. Observations of copulation in koala are rare, but one study reported the presence of a coagulum plug in the vaginal os of a female koala after 8 serial matings (Smith, 1979). The koala coagulum recovered after electroejaculation may be similar to the gel-type material infrequently observed in the ejaculate of Virginia opossum (Didelphis virginiana; Hartman, 1924) and brush tail possum (Howarth, 1950; Kean et al., 1964).

Examination of necropsy material reveals that a koala spermatozoon differs markedly from that of most other marsupials, both in spermiogenesis and overall structure (Tyndale-Biscoe $\&$ Renfree, 1987). Hughes (1965) compared the morphology of sperm from 18 marsupial species and first described the 'strongly recurved hooked' features of the koala spermatozoon. Subsequent ultrastructural studies have identified additional unique characteristics in the koala spermatozoon, including uneven condensation of the chromatin during nuclear development, a mode of nuclear flattening, which results in an unusual and 'eutherian-like' neck insertion, and variants in acrosome development and internal organization of the mitochondria of the middle piece (Harding et al. 1987). Clearly, the present studies confirmed the earlier gross observations of Hughes (1965) and demonstrated considerable variability in head shape of freshly ejaculated sperm. The significance of this heterogeneity is being examined in electron microscopy studies (P. Temple-Smith \& D. Taggart, unpublished). Hughes (1965) observed that the head region of the koala spermatozoon is only slightly curved upon entering the caput of the epididymis and appears to become more tightly bent with passage through the epididymis, suggesting that the variety of head forms observed may represent different degrees of nuclear maturation. 
The main androgen secreted by all marsupials studied to-date appears to be testosterone (Tyndale-Biscoe \& Renfree, 1987). Circulating concentrations of testosterone in representative species of Dasyuridae, Phalangeridae and Macropodidae are $\sim 4$-fold higher or more (see review, Tyndale-Biscoe \& Renfree, 1987) than observed in the free-living koalas here. The limitations imposed in our study prevented detailed examination of temporal testosterone patterns, and it is possible that the capture procedure and any associated stressors may have perturbed the system so that measured concentrations were not normative. However, it appears that, if a stress response was provoked, it did not elicit a consistent response among males. We observed that circulating testosterone increased, decreased or both in slightly fewer than half the serial-sampled males. None the less, consistent decreases in serum testosterone concentrations were observed in $\sim 30 \%$ of the test group. To understand the regulation of the pituitary-gonadal axis of this species more clearly, more-detailed studies are warranted and are possible, given our finding that koalas readily tolerate serial blood sampling

The koala populations differed in seminal features, especially in sperm concentration and motility characteristics. Males from the large, less geographically isolated Brisbane Ranges population consistently produced higher-quality electroejaculates than the 2 island populations. Previous studies from our laboratories have identified one other free-ranging mammal, the lion, in which semen characteristics vary with geographic distribution (O'Brien et al., 1987; Wildt et al., 1987). Understanding population differences for koalas may be more difficult because of our poor understanding of the effects of other factors on male reproductive function. For example, the fewest motile sperm/ejaculate were recovered from the koalas of Phillip Island, a population where $78 \%$ of all animals are infected with Chlamydia (Lee \& Martin, 1988). Nevertheless, the careful integration of genetic and environmental factors with reproductive performance will continue to be a major priority for effectively managing rare species living in threatened habitats.

Reproductive studies of the koala have been limited, in part, by the premier status of the species in Australia. The koala's anthropomorphic features (Lee \& Martin, 1988) and an anecdotal consensus that the species is susceptible to manipulatory stress have restricted access for 'invasive' studies. Several lines of evidence suggest that the koala can withstand more-aggressive research approaches and, thus, deserves more intense study. Free-living koalas are experiencing 2 major paradoxical threats. In certain populations, disease or other factors allow $<40 \%$ of all adults to reproduce (Lee \& Martin, 1988), which, in the context of further habitat fragmentation, inevitably reduces genetic variability. In contrast, disease-free populations often increase rapidly in size, resulting in severe habitat defoliation and the mandatory relocation of animals (Martin \& Lee, 1984; Lee \& Martin, 1988). A better understanding of the reproductive physiology of the species could alleviate subfertility or sterility problems or allow the control of fertility in rapidly expanding populations. Preliminary data on adrenal function suggest that circulating cortisol concentrations in koalas are low (Booth et al., 1988). The capture of wild koalas does not appear to elicit an acute cortisol response and there is no apparent correlation between circulating glucocorticoid concentrations and reproductive success in wild populations (McDonald et al., 1988). Finally, our results demonstrated the relative ease and safety of collecting large numbers of motile sperm from the koala. All of the study animals tolerated the described capture, anaesthetic, serial blood sampling and electroejaculation procedures well with no adverse effects. Previously captured males were identified feeding in trees within $24 \mathrm{~h}$ of semen collection. Our observations indicate that the species is probably resilient to these manipulatory procedures, which suggests that more-detailed empirical studies of gamete physiology and endocrinology should be encouraged.

The authors thank Dr J. Brown for validating the testosterone radioimmunoassay; Drs $\mathrm{R}$. Martin, K. Handasyde, P. Temple-Smith and J. Rodger for advice and information; and S. Hurlbut and M. Treadwell for technical assistance. This project was supported, in part, by Friends of the National Zoo, Qantas Airlines, the Research Opportunities Fund of the Smithsonian Institution (to D.E.W. and M.B.) and the Australian Research Grants Scheme (to J.A.M.G. and 
N.D.M.). Samples were collected under the authority of the Victorian Department of Conservation, Forests and Lands Permit No. 88-008.

\section{References}

Biggers, J.D., Whitten, W.K. \& Whittingham, D. (1971) The culture of mouse embryos in vitro. In Methods of Mammalian Embryology, pp. 86-116. Ed. J. G. Daniel. Raven Press, New York.

Booth, R., MacFarlane, J., Osawa, R.O. \& Carrick, F. (1988) Aspects of adrenal function in the koala. Proc. 3rd. Symp. Biol. Koala, Melbourne.

Brown, S. (1988) Reproduction in the female koala (Phascolarctos cinereus) in Queensland. Proc. 3rd. Symp. Biol. Koala, Melbourne.

Brown, A.S., Carrick, F.N., Gordon, G. \& Reynolds, K. (1984) Diagnosis and epidemiology of an infertility disease in the female koala. Vet. Radiol. 25, 242-248.

Brown, J.L., Goodrowe, K.L., Simmons, L.G., Armstrong, D.L. \& Wildt, D.E. (1988) Evaluation of the pituitarygonadal response to $\mathrm{GnRH}$, and adrenal status, in the leopard (Panthera pardus japonensis) and tiger (Panthera tigris). J. Reprod. Fert. 82, 227-236.

Bush, M., Wildt, D.E., O'Brien, S.J. \& Graves J.A. (in press) Dissociative anesthesia (Telazol) in freeranging male koalas (Phascolarctos cinereus) and comparative data on selected marsupials in captivity. Aus. Vet. J..

Carlisle, C.H., Brown, A.S., Filippich, L.J., Reynolds, K. \& Reynolds, W.T. (1989) Intravenous urography in the koala (Phascolarctos cinereus). Vet. Radiol. 30, $34-40$.

Gordon, G. (1988) Queensland koala populations: controlling factors. Proc. 3rd Symp. Biol. Koala, Melbourne.

Handasyde, K.A. (1986) Factors affecting reproduction in the female koala (Phascolarctos cinereus). Ph.D. thesis Monash University, Clayton.

Handasyde, K.A., McDonald, I.R., Than, K.A. \& Michaelides, J. (1988) Reproductive hormones and reproduction in the koala. Proc. 3rd Symp. Biol. Koala, Melbourne.

Harding, H.R. (1979) Affinities of the koala on the basis of sperm ultrastructure. Aust. Mamm. Soc. Bull. 6, 22-23.

Harding, H.R., Carrick, F.N. \& Shorey, C.D. (1987) The affinities of the koala, Phascolarctos cinereus (Marsupialia), on the basis of sperm ultrastructure and development. In Possums and Opossums: Studies in Evolution, pp. 353-364. Ed. M. Archer, Royal Zoological Society of New South Wales, Sydney.

Hartman, C.G. (1924) Observations on the motility of the opossum genital tract and the vaginal plug. Anat. Rec. 27, 293-303.

Howard, J.G., Bush, M. \& Wildt, D.E. (1986) Semen collection, analysis and cryopreservation in nondomestic mammals. In Current Therapy in Theriogenology, pp. 1047-1053. Ed. D. Morrow. Alan R. Liss Inc., Philadelphia.

Howarth, V.S. (1950) A method for the collection of the secretions of the individual accessory sex glands in a marsupial (Trichosurus vulpecula). Med. J. Aust. 1959i, 566-567.
Hughes, R.L. (1965) Comparative morphology of spermatozoa from five marsupial families. Aust. J. Zool. 13, 533-543.

Kean, R.I., Marryatt, R.G. \& Carroll, A.L.K. (1964) The female urogenital system of Trichosurus vulpecula (Marsupialia). Aust. J. Zool. 12, $18-41$.

Lee, A. \& Martin, R. (1988) The Koala: A Natural History. New South Wales University Press, Kensington.

McColl, K.A., Martin, R.W., Gleeson, L.J., Handasyde, K.A. \& Lee, A.K. (1984) Chlamydia infection and infertility in the female koala (Phascolarctos cinereus). Vet. Rec. 115, 655 .

McDonald, I.R., Handasyde, K.A., Than, K.A. \& Michaelides, J. (1988) Factors affecting plasma adrenocortical hormone concentration in captive and free-ranging koalas. Proc. 3rd. Symp. Biol. Koala, Melbourne.

McNally, J. (1957) A field survey of a koala population. Proc. Roy. Zool. Soc. N.S.W. pp. 18-27.

Martin, R.W. \& Lee, A. (1984) The koala, Phascolarctos cinereus, the largest marsupial folivore. In Possums and Gliders, pp. 463-467. Eds A. P. Smith \& I. D. Hume. Surrey Beatty \& Sons, Sydney.

O'Brien, S.J., Martenson, J.S., Packer, C., Herbst, L., de Vos, V., Joslin, P., Ott-Joslin, J., Wildt, D.E. \& Bush, M. (1987) Biochemical genetic variation in zoogeographic isolates of African and Asiatic lions. $\mathrm{Nat}$. Geo. Res. 3, 114-124.

O'Donoghue, C.H. (1916) On the corpora lutea and interstitial tissue of the ovary in the Marsupialia. Q.J. micro. Sci. 61, 433-473.

Poole, W.E. \& Pilton, P.E. (1964) Reproduction in the grey kangaroo, Macropus canguru, in captivity. CSIRO, Wildl. Res. 9, 218-234.

Pursel, V.G. \& Johnson, L.A. (1974) Glutaraldehyde fixation of boar spermatozoa for acrosomal evaluation. Theriogenology 1, 63-68.

Reed, P.C., Lunney, D. \& Walker, P. (1988) An ecological interpretation of the distribution of the koala (Phascolarctos cinereus) in New South Wales (19471987). Proc. 3rd. Symp. Biol. Koala, Melbourne.

Rodger, J.G. (1978) Male reproduction: its usefulness in discussions of Macropodidae evolution. Aust. Mammal. 2, 73-80.

Rodger, J.G. \& Hughes, R.L. (1973) Studies of the accessory glands of male marsupials. Aust. J. Zool. 21, 303-320.

Rodger, J.G. \& Pollitt, C.C. (1981) Radiographic examination of electroejaculation in marsupials. Biol. Reprod. 24, 1125-1134.

Rodger, J.G. \& Suter, D.A.I. (1978) Respiration rates and sugar utilization by marsupial spermatozoa. Gamete Res. 1, 111-116.

Rodger, J.G. \& White, I.G. (1975) Electroejaculation of Australian marsupials and analyses of the sugars in the seminal plasma from three macropod species. $J$. Reprod. Fert. 43, 233--239.

Rodger, J.G. \& White, I.G. (1978) The collection, handling and some properties of marsupial semen. In 
Artificial Breeding of Non-domestic Species, pp. 289 301. Ed. P. F. Watson. Academic Press, London.

Smith, M. (1979) Notes on reproduction and growth in the koala, Phascolarctos cinereus (Goldfuss). Aust. Wildl. Res. 6, 5-12.

Temple-Smith, P. \& Taggart, D. (1988) On the male generative organs of the koala: an update. Proc. $3 r d$. Symp. Biol. Koala, Melbourne.

Todhunter, R. \& Gemmell, R.T. (1987) Seasonal changes in the reproductive tract of the male marsupial bandicoot, Isoodon macrourus. J. Anat. 154, 173-186.

Tyndale-Biscoe, H. \& Renfree, M. (1987) Reproductive Physiology of Marsupials. Cambridge University Press, Cambridge.

Warneke, R.M. (1978) The status of the koala in Victoria. In The Koala, Proceedings of the Taronga Symposium, pp. 109-123. Ed. T. J. Bergin. John Sands Pty. Ltđ, Artarmon.

Wildt, D.E., Bush, M., Howard, J.G., O'Brien, S. J., Meltzer, D., van Dyk, A., Ebedes, H. \& Brand, J.D. (1983) Unique seminal quality in the South African cheetah and a comparative evalution in the domestic cat. Biol. Reprod. 29, 1019-1025.

Wildt, D.E., Bush, M., Goodrowe, K.L., Packer, C., Pusey, A.E., Brown, J.L., Josling, P. \& O'Brien, S.J. (1987) Reproductive and genetic consequences of founding isolated lion populations. Nature, Lond. 329, 328-331.

Wildt, D.E., Phillips, L.G., Simmons, L.G., Chakraborty, P.K., Brown, J.L., Howard, J.G., Teare, A. \& Bush, M. (1988) A comparative analysis of ejaculate and hormonal characteristics of the captive male cheetah, tiger, leopard and puma. Biol. Reprod. 38, 245-255.

Wildt, D.E., Bush, M., Morton, C., Morton, F. \& Howard, J.G. (1989) Semen characteristics and testosterone profiles in ferrets kept in a long-day photoperiod, and the influence of hCG timing and sperm dilution on pregnancy rate after laparoscopic insemination. J. Reprod. Fert. 86, 349-358.

Received 17 July 1990 